\title{
Multicultural Mentorship Education: A Critical Tool for National Unity and Integration in Nigeria
}

\author{
Ekima Tina Salako \\ Department of Social Studies Education \\ National Teachers' Institute, Nigeria.
}

\begin{abstract}
The learner population is constantly changing, so, educators deal with learners from a wide cross-section of cultural backgrounds. Consequently, there is need to focus on help-seeking behaviors and help-providing behaviors of mentors based on race, social class and ethnicity. There is always the concern that most schools may not be adjusting rapidly enough to the fact that learners from different cultures may need an alternative style of teaching and learning in order to realize their optimal potential in the global 21st century classroom. In realizing this view of social and cultural differences in the behavior of the minority students, as a matter of need, an appropriate education of citizens through multicultural mentorship education is being advocated. As traditionally defined, mentoring is a one-to-one relationship between an experienced and a less experience person over a period of time. Mentors empower students' success by being role models and guide as a result of challenges which come from a variety of sources. Therefore, this paper investigated multicultural mentorship education as a critical tool for national unity and integration. One research question was raised and a null hypothesis was generated and tested at 0.05 level of significance. The study adopted a quasi experimental design. Participants were one hundred and fifty junior secondary III students purposively selected from three secondary schools in Ogun State, South-West region of Nigeria. Data were analyzed using descriptive statistics of frequency count, percentage, mean and standard deviation. Inferential statistics of Pearson product moment correlation was used to test the hypothesis. The findings of this study revealed that effective refocusing of traditional or conventional teaching method with a view of complimenting it with multicultural mentorship educational strategy would enhance service delivery plus national unity and integration.
\end{abstract}

Keyword: Multicultural, Mentorship, Cultural background, National Unity, Integration.

\section{INTRODUCTION}

A mentor is an experienced person who advises and helps somebody with less experience over a period of time. This would save the mentee the risk of learning by trial and error which could be burdensome and time wasting. The term mentor stems from Greek mythology in which Odysseus entrusted the care and education of his child to a friend named Mentor while he was away on his adventures and travels. Odysseus was one of the greatest of the Greek heroes who fought during the Trojan War [19].Known for his cunning intellect, Odysseus crafted the plan that destroyed the city of Troy and ended the Trojan War [9]. Historically significant systems of mentorship include the guru - disciple tradition practiced in Hinduism and Buddhism, Elders, the discipleship system practiced by Rabbinical Judaism and the Christian church, and apprenticing under the medieval guild system.

Odiorne [21] avers that in the United States of America, advocates for workplace equity in the second half of the twentieth century popularized the term "mentor" and concept of career mentorship as part of a larger social capital lexicon. Mentoring has come to be used for a 
variety of relationships. Some of its synonyms include role model, coach, guide, sponsor, friend and adviser. Although the idea of mentoring is not a new one, in recent years, there has been an increased focus on programs designed to facilitate both formal and informal mentoring relationships. Practitioners, researchers, policy makers, and funders all look at mentoring as a promising form of intervention for children and youth. In many secondary and post-secondary schools, mentorship programs are offered to support students in program completion, confidence building and transitioning to further education or the workforce [8].

According to DuBois and Karcher [14], reports suggest that there are at least 4,500 agencies providing mentoring, so, the idea of mentoring is not new. However, mentorship education is not popular in Nigeria which is the focus of this study. Consequent upon cultural diversities in virtually all classrooms in Nigeria; Ojebiyi and Salako [22] suggest that educators should create culturally responsive teaching and learning strategies that can help students understand and negotiate differences across culture. Importantly, the growing spate of ethno-religious crisis and insurgency that characterize the Nigerian polity have been traced partially to inadequacies in the teaching of multicultural concepts in schools. The teaching and learning of these concepts through multicultural mentorship strategies could discourage discrimination and promote mutual respect for other cultures.

Incorporating quality mentoring programs could address issues like school attendance, course performance and behavior among students [4]. More of these "mentor mobilizers" are needed in our nation's schools to ensure students have the additional support they need to succeed. Mentors are not tutors, editors, nor can they negotiate grades with a student's instructors. The mentor is advised to refer the student to the appropriate services on campus. Mentors will facilitate students' development of goals and objectives [29]. Although a mentor may not be an expert in all areas that students may need, the mentor will be an accessible guide in referring students to the correct resource either on campus or off campus. In this context, it has been claimed that the preparation of mentors has to be a priority for policymakers, teacher educators and researchers [18].Therefore, multicultural mentorship education is being promoted in this work.

\section{MENTORING TECHNIQUES}

The focus of mentoring is to develop the whole person and so the techniques are broad and require wisdom in order to be used appropriately. Different techniques may be used by mentors according to the situation and the mindset of the mentee.

Formal Mentoring: Formal mentoring refers to a structured process supported by the organization and addressed to a target population. Formal mentoring differs from informal mentoring in that the organization develops a program and process for mentoring to take place. The relationship is usually short-term (one year) formally, with the hope that it will develop informally over the long-term. The mentors are volunteers, or should be, but they are still chosen. The mentees are assigned or strongly encouraged to participate. The mentee and mentor may or may not voluntarily choose each other [13]. Most research states the mentor should not be a supervisor, but some research is beginning to counter that theory. In a formal mentoring program, there are certain processes and activities that should take place to give the relationship the best chance for success.

Here, some ten to fifteen students from a department are assigned to a faculty member for both academic advising as well as some conversation around other life issues [24]. Mentees are matched with mentors by a designated mentoring committee or mentoring administrator 
usually consisting of senior members of the Training, Learning and Development and Human Resources departments. The matching committee reviews the mentoring profiles and makes matches based on areas for development, mentor strengths, overall experience, skill set, location and objectives for the mentorship. The responsibilities of a mentor are to teach, inspire, motivate and empower the mentee.

Discussion topics may range from academic issues to various programs and services [24]. The mentee can expect regular contact from the mentor and ask for guidance when academic questions or frustrations arise. The mentoring relationship will be established for one academic year - fall and spring semesters. The report details a powerful mentoring effect. Young peoples' experiences back up previous research that has shown that mentoring, when done right, can result in better attendance at school, improve behavior and relationships in school, and drive academic achievement [25].

Informal Mentoring: Informal mentoring is the natural coming together of a mentor and mentee. This is done in friendship, through personal and professional respect and admiration from each to the other. It is usually a long-term relationship. The U.S. Department of Transportation Mentoring Handbook [12] states that a successful mentor is characterized as supportive, patient, and respected, a person who wants to share their experiences, and who facilitates personal and professional growth in the mentee. Multiple mentorship is also a new and upcoming trend under informal mentoring. Having more than one mentor will widen the knowledge of the person being mentored. There are different mentors who may have different strengths. This can be helpful because we can all learn from each other.

Notably, a mentoring relationship can be as much for the mentor as the mentee. A mentor will set up a meeting schedule with the mentee. Each pair can communicate and get together as often as they like. Some may wish to meet as frequently as twice a month; others may communicate primarily by phone or e-mail. When a student demonstrates the early signs of falling off track, mentoring should be central part of the supports put in place to get that student back on the path to graduation [10]. Yet, our systemic approach excludes this focus on the need for meaningful adult support as a gateway to achievement but wholly focused on academic content [10].

\section{Mentoring and Diversity}

In these early years of the 21st century, large-scale human migration is a global phenomenon. This massive relocation of cultural groups is both optional (e.g. people seeking economic advantage) or forced (e.g. as a result of conflict or environment degradation). Many of these migrating populations seek to develop a new life in these new environments. As a result of these migrations, contemporary societies are becoming more diverse and multi-ethnic in nature, especially in the urban environments of large cities [17]. These changing demographics are especially apparent at the school level and are having a major impact on the work of educators, particularly those in formal leadership positions within the school [7]. Therefore, the development and consequent need for a multicultural mentoring approach is the direct result of the multicultural and pluralistic nature of the modern, global and internationalized society. This is germane in order for students to realize their optimal potential.

Diversity Mentoring is one of the top ways to innovate, it is all about bringing in new ideas. Mentors can empower diverse employees to share ideas, knowledge and experience to expand and innovate into the company. This also brings cultural awareness and a value of other 
cultures into the workplace. In the last 10 years, the minority population increased by $35 \%$ compared to $3.4 \%$ increase for the Caucasians, non-Hispanic population [28]. According to Census projections, within 20 years, over one-third of the U.S. population will be comprised of people from minority groups [28]. Mainstream perceptions of diversity in the academy have been shown as pejorative with stereotypes, such as the belief that minorities and women are less able and less talented [27]. Mentors can assist in developing strategies to assist minorities and women in confronting and overcoming social and organizational cultural barriers in higher education organizations.

Ragins and Kram [27] found that individuals were most successful engaging in mentoring relationships if they had positive attitudes towards diversity and had some prior experiences in racially heterogeneous interactions. Enuoka [16]; Mohammed [20] are both of the opinion that effective management of diversity in the society is no doubt a challenge because Nigeria provides one of the best case studies of ethno-religious conflicts. The country has witnessed so many ethno-religious crises with attendant loss of precious lives and properties as a result of intolerance for other people's cultures [2]. Therefore, as a matter of need, an appropriate education of citizens could contribute to national development by equipping them with adequate knowledge of how to work and live together harmoniously in any society. Such an appropriate education is multicultural mentorship studies. While the basic value of mentoring may be either an organizational or personal benefit to the mentor, the possibility exists that the relationship may develop into a friendship that lasts a lifetime.

\section{Conventional Teaching Method}

The conventional teaching method is still the most frequently used mode of instruction in most Nigerian schools today [23]. The techniques involved in the method serve as the basis for other methods of training. Conventional method is a teaching strategy whereby an instructor is the central focus of information transfer. Typically, an instructor will stand before a class and present information for the students to learn. Sometimes, they will write on a board or use an overhead projector to provide visuals for students. Students are expected to take notes while listening to the instruction. One of its advantages is that it is possible to educate large number of people at once, thereby lowering costs. It creates interest in a subject as teachers transmit enthusiasm about their discipline thereby serving as a role model for the students [5].

Similarly, Ojebiyi and Salako [22] aver that the most practiced method of teaching and learning is mostly referred to as the conventional teaching method, which is the model for most schools. The method is still used in schools today because of the unprecedented expansion in the school enrolment, shortage of infrastructures coupled with shortage of funds. However, the conventional teaching method is not the most effective according to [23] because it focuses entirely on intellectual and ignores experiential learning. This style of learning is intended to allow students gain an individual meaning to the subject matter [5]. It teaches students how to succeed on standardized tests and relies mostly on the use of the intellect [3].

However, Doymos [13] explains that research has shown that students learn by doing, thinking critically about concepts and then applying their knowledge to diverse situations. Therefore, there is need for the use of alternative instructional strategies to compliment teaching method. This will help ensure that most schools adjust rapidly enough to the fact that learners from different cultures may need an alternative style of teaching and learning in order to realize their optimal potential in the global 21st century classroom. Hence, multicultural mentorship strategy is being examined as a complimentary mode of instruction. 


\section{Hypothesis}

\section{MATERIALS AND METHODS}

One null hypothesis was generated and tested at 0.05 level of significance

H01: There is no significant main effect of treatment on students'

i. Knowledge of multicultural mentorship education

\section{Research Question}

A research question was raised and tested at 0.05 level of significance

1. Can multicultural mentorship education promote peaceful co-existence among citizens?

\section{Research Design}

The study adopted the pretest-posttest, control group, quasi-experimental design.

\section{Selection of Participants}

Participants were one hundred and fifty junior secondary III students purposively selected from three secondary schools in Ogun State, South West region of Nigeria.

\section{Research Instruments}

Two instruments used to generate and collect data for this study were: Multicultural Concepts Knowledge Test (MCKT) and Multicultural Concepts Attitude Scale (MCAS). For the Multicultural Concepts Knowledge Test, the reliability coefficient using Cronbach alpha 20 is $\alpha$ $=0.78$. Using Cronbach alpha, the Multicultural Concept Attitude Scale has its reliability coefficient $\alpha=0.82$.

\section{Data Analysis}

Data were analyzed using descriptive statistics of frequency count, percentage, mean and standard deviation. Inferential statistics of Pearson product moment correlation was used to test the hypothesis.

\section{RESULTS}

Table I: Summary of Pearson Moment Correlation (PPMC) by Treatment

\begin{tabular}{|l|l|l|l|l|l|l|}
\hline Variables & N & Mean & Std D & R & P & Remark \\
\hline Multicultural mentorship group & 75 & 16.43 & 5.80 & 0.305 & 0.000 & Significant \\
\hline Conventional teaching group & 75 & 15.98 & 3.77 & & & \\
\hline
\end{tabular}

From table 1, there is significant effect of treatment on students' posttest knowledge scores in multicultural concepts $(\mathrm{r}=0.305 ; \mathrm{p}<.05)$. This means that there is significant difference in the adjusted posttest scores of students exposed to the multicultural mentorship learning and conventional instructional strategy. Hence, hypothesis 1 is rejected.

Table II reveals that the students agreed that Multicultural mentorship education could lay good foundation for students $\bar{x}=3.24$ )Mentorship could give students the right focus in life $\bar{x}=3.41$ ). They also agreed that Multicultural mentorship education could promote peaceful co-existence $\bar{x}=2.88$ ), that there are ethnic crises and discrimination in schools $\bar{x}=2.63$ ), that most of them do not know the functions of a good mentor $\bar{x}=3.45$ ), most students agreed that multicultural mentorship education must be offered in secondary schools $\bar{x}=3.29$ ), that Multicultural mentorship education could equip students with skills for solving societal problems $\bar{x}=2.73$ ).Multicultural mentorship education would discourage 
students from voluntarily participating in civic duties $\bar{x}=2.80$ ). Table 11 shows that multicultural mentorship education can promote peaceful co-existence among citizens.

Table II: Answering the Research Question

Can multicultural mentorship education promote peaceful co-existence among citizens?

\begin{tabular}{|c|c|c|c|c|c|c|c|}
\hline No & Statement & SA & $\mathbf{A}$ & D & SD & Mean & Std D \\
\hline 1 & $\begin{array}{l}\text { Multicultural mentorship education can } \\
\text { lay good foundation for students }\end{array}$ & $\begin{array}{l}81 \\
(54.0)\end{array}$ & $\begin{array}{l}46 \\
(30.7)\end{array}$ & $\begin{array}{l}11 \\
(7.3)\end{array}$ & $\begin{array}{l}2 \\
(1.3)\end{array}$ & 3.24 & 1.10 \\
\hline 2 & $\begin{array}{l}\text { Multicultural mentorship education } \\
\text { could promote peaceful co-existence }\end{array}$ & $\begin{array}{l}54 \\
(36.0)\end{array}$ & $\begin{array}{l}62 \\
(41.3)\end{array}$ & $\begin{array}{l}11 \\
(7.3)\end{array}$ & $\begin{array}{l}8 \\
(5.3)\end{array}$ & 2.88 & 1.24 \\
\hline 3 & $\begin{array}{l}\text { There are ethnic crises and } \\
\text { discrimination in schools }\end{array}$ & $\begin{array}{l}41 \\
(27.3)\end{array}$ & $\begin{array}{l}58 \\
(38.7)\end{array}$ & $\begin{array}{l}20 \\
(13.3)\end{array}$ & $\begin{array}{l}17 \\
(11.3)\end{array}$ & 2.63 & 1.26 \\
\hline 4 & $\begin{array}{l}\text { Most Students do not know the } \\
\text { functions of a good mentor }\end{array}$ & $\begin{array}{l}65 \\
(43.3)\end{array}$ & $\begin{array}{l}73 \\
(48.7)\end{array}$ & $\begin{array}{l}6 \\
(4.0)\end{array}$ & $\begin{array}{l}4 \\
(2.7)\end{array}$ & 3.45 & 1.11 \\
\hline 5 & $\begin{array}{l}\text { Multicultural mentorship education } \\
\text { could equip students with skills for } \\
\text { solving societal problems }\end{array}$ & $\begin{array}{l}35 \\
(23.3)\end{array}$ & $\begin{array}{l}64 \\
(42.7)\end{array}$ & $\begin{array}{l}31 \\
(20.7)\end{array}$ & $\begin{array}{l}15 \\
(10.0)\end{array}$ & 2.73 & 1.64 \\
\hline 6 & $\begin{array}{l}\text { Multicultural mentorship education } \\
\text { would discourage students from } \\
\text { voluntarily participating in civic duties }\end{array}$ & $\begin{array}{l}48 \\
(32.0)\end{array}$ & $\begin{array}{l}51 \\
(34.0\end{array}$ & $\begin{array}{l}29 \\
(19.3)\end{array}$ & $\begin{array}{l}17 \\
(11.3)\end{array}$ & 2.80 & 1.11 \\
\hline 7 & $\begin{array}{l}\text { Multicultural mentorship education } \\
\text { must be offered in secondary schools }\end{array}$ & $\begin{array}{l}72 \\
(48.0)\end{array}$ & $\begin{array}{l}61 \\
(40.7)\end{array}$ & $\begin{array}{l}6 \\
(4.0)\end{array}$ & $\begin{array}{l}11 \\
(7.3)\end{array}$ & 3.29 & 0.86 \\
\hline 8 & $\begin{array}{l}\text { Mentorship could give students the } \\
\text { right focus in life }\end{array}$ & $\begin{array}{l}97 \\
(54.7)\end{array}$ & $\begin{array}{l}34 \\
(22.7)\end{array}$ & $\begin{array}{l}10 \\
(6.7)\end{array}$ & $\begin{array}{l}2 \\
(1.3)\end{array}$ & 3.41 & 1.01 \\
\hline
\end{tabular}

\section{DISCUSSION}

It was found in this study that the effect of treatment on students' knowledge of multicultural concepts is significant. This is to the effect that the multicultural mentoring strategy was more effective than the conventional teaching method. The superiority of the multicultural mentorship mode of instruction over the conventional strategy is founded upon the nature of interaction among the students and their mentors in the learning situation. For instance, students worked together in small heterogeneous groups, sharing ideas, experiences and were more or less in charge of the activities as mentors only acted as facilitators. Within each group, students from diverse cultural, ethnic were provided equal opportunities and interacted to achieve common goals. Also, students of different levels of abilities used the variety of learning activities provided to improve on their understanding of the multicultural concepts within inter group and intra group setting. Indeed, the multicultural mentoring strategy fostered greater student attention and stimulated interest through the exploration of the different cultures presented to them. 
Further, the findings showed that on attitude to multicultural concepts, students' attitude to multicultural concepts is significant. These show that despite the fact that school subjects like social studies, civic education and religious studies are being taught in schools, there are ethnic crises and discrimination the students behavior are still not positive but negative. Multicultural mentorship education must be offered in secondary schools in order to lay good foundation and inculcate in the students skills to function properly in the society, DuBrin [15]; Ojebiyi and Salako [23] both agree that the conventional teaching method is not the best because it ignores experiential form of learning and relies mostly on intellectual development. Therefore, conventional teaching method could be complemented using other strategies for effective teaching and learning.

In a similar perspective, Adekunle [1] is of the opinion that there are many teaching methods and techniques associated with the integrated Social Studies, there is no single mode of teaching which fits all the learning situations. Hence, conventional teaching method should not be out rightly condemned. Mentoring appears to be one of those good, win-win ideas we affirm but have difficulty implementing. Mentoring is good for the mentor, the mentee, and the organization. This good idea should therefore be widely adopted and practiced in schools as agreed in table 11 above. Mentors empower students' success by being a role model and a guide as a result of challenges which come from a variety of sources [29]. Therefore, mentors help to reinforce students' learning while experiencing realistic situations, applying practical knowledge and connecting with the community. Hence, multicultural mentoring strategy is an effective teaching strategy which is aimed at accommodating learners from diverse cultural backgrounds.

\section{CONCLUSION}

Based on the findings of the study, it could be concluded that the use of multicultural mentorship instructional strategy has the potentials of helping to foster cooperation, mutual trust, understanding, more effective communication sharing of other peoples' world views can ultimately lead to improved knowledge of students in multicultural societies. Also, in employing the strategy in classroom, students' ethnic origins are relevant. Hence, among the citizens, peaceful co-existence will tend to hold sway in different parts of the country if multicultural mentorship is given a pride of place in Nigerian Secondary Schools.

Multicultural mentoring learning strategy offers an opportunity for students to get exposed to people, events and the opportunity to make connections with others. There is need to create an environment where all races and cultures of the world would learn to respect their differences. An overall goal of Social Studies is to create a place where all students can live as responsible citizens in a pluralistic society. In realizing this view, if this strategy is implemented effectively and vigorously, it may indeed contribute to the enhancement of peaceful co- existence between learners in multicultural schools and the society at large.

Less emphasis should be placed on conventional method of teaching because it focuses mostly on intellectual development and ignores experiential learning. It teaches students how to succeed on standardized tests and relies mostly on the use of the intellect. Instructors also tend to have a greater control over what is being taught in the classroom because they are partially the sole source of information. Obviously, this teaching method has partially failed to bring about the desired outcome of interactive learning. Therefore, there is the need for teachers to use other teaching strategy such as multicultural mentoring strategy to complement the conventional teaching method. 
There is need to work together to identify youth who could benefit most from a mentor, determine their specific mentoring needs, and match them to quality mentors and other wraparound services. This intentional relationship building could dramatically improve the lives of children and their ability to achieve the culture of schools and the fabric of communities. That is because the mentoring effect impacts not only the student and mentor. It is also a critical link in the chain of outcomes for our youth, it could help them to become more productive and active citizens ready to seize the opportunities that lie ahead. Practitioners, researchers, policy makers should promote mentoring because it is a promising form of intervention for children and youth. The presence of a mentor in the life of a young person not only supports healthy growth and development but also serves as a protective factor against many of the risks facing today's youth.

\section{References}

1. Adekunle, M.O. 2008. Methods and resources in teaching Social Studies. fromhttp://www.ijeunilorin.net/alphabeticlist.php

2. Ajiboye, J.0. 2010. Social Studies education in Nigeria and emerging issues. Adeniran Ogunsanya college of education journal of Social Studies education in Nigeria.Vol 1(1) pp 1-7.

3. Ajitoni, S.O. and Salako, E.T. 2013. Effects of cooperative learning and field trip strategies on secondary school students' knowledge of and attitudes to multicultural concepts in Social Studies. Journal of education and practice. Vol.4 (22),pp 35-42. www.iiste.org

4. Allen, TD.; Eby, LT.; Lentz, E (2006). "Mentorship behaviors and mentorship quality associated with formal mentoring programs: closing the gap between research and practice". Journal of Applied Psychology 91 (3): 567-578. doi:10.1037/0021-9010.91.3.567. PMID 16737355.

5. Anise, A.C. and Ojedokun, O.E. 2006. Instructional methods in the classroom in Ehindero, O.J.\&Aladejana, F.O. (eds). Introduction to teaching profession, Lagos: Lantern books.

6. Banks, J. A. 2006. Cultural diversity and education (5th ed.). Boston: Allyn \& Bacon Banks, J. A. 2004. Multicultural education: Historical development, dimensions and practice. In J. A Banks \& C. A. McGeeBanks (Eds.). Handbook of research on multicultural education. New York, New York: Macmillan publishing company.

7. Bozeman, B.; Feeney, M. K. (October 2007). "Toward a useful theory of mentoring: A conceptual analysis and critique". Administration \& Society 39 (6): 719-739. doi:10.1177/0095399707304119.

8. Brann, E.and Homeric M.(2002) : Clues to Delight in Reading the Odyssey and the Iliad. Philadelphia: Paul Dry Books,

9. Daloz, L. A. (1990). Effective Teaching and Mentoring. San Francisco: Jossey Bass. p. 20.

10. Cotton, J. L., Miller, J. S., and Ragins, B. R. 2000. Marginal mentoring: The effects of type of mentor, quality of relationship, and program design on work and career attitudes. Academy of Management Journal, 43(6), 1177-1194.

11. Departmental Office of Human Resource Management. DOT mentoring handbook. U.S. Department of Transportation www.au.af.mil/au/awc/awcgate/mentor/mentorhb.htm

12. Doymus, K. (2008). Teaching chemical equilibrium with the jigsaw technique. Research in science education 38 (2), pp 249-260.

13. DuBois DL, Karcher MA, editors. Handbook of youth mentoring. Thousand Oaks, CA: Sage; 2005

14. DuBrin, A.J. 2004. Applying psychology: Individual \& organizational effectiveness. New Jersey: Pearson.

15. Enuoka, L.O. 2005. Managing ethno-religious violence and area differentiation in Kaduna metropolis, in A.M. Yakubu et al (eds) Crisis and conflict management in Nigeria. Since 1980. Vol. 2. pp. 633 Baraka press and publishers Ltd., Kaduna, Nigeria.

16. Gay, G. (2000). Culturally responsive teaching: Theory, research, and practice. New York: Teachers College Press. 
17. Hobson A.J., Ashby P., Malderez A., Tomlinson P.D. Mentoring beginning teachers: what we know and what we don't. Teaching and Teacher Education, 25 (1) (2009), pp. 207-216

18. Inzer, L.D and Crawford, C.B.A Review of Formal and Informal Mentoring: Processes, Problems, and Design Journal of Leadership Education.Volume 4, Issue 12005 Pgs 31-50

19. Mohammed, H. 2004. Plateau. crises: The press as the No.1. Culprit, Daily Trust, June 30.

20. Odiorne, G. S. (1985). "Mentoring - An American Management Innovation". Personnel Administrator (30): 63-65.

21. Ojebiyi, O.A. and Salako, E.T 2013.Effect of concept mapping instructional strategy on junior secondary school student's knowledge of multiculturalism in the global 21st century Social Studies classroom. Journal of education and practice. www.iiste.org. vol.4 (13), pp 15-21.

22. Ojebiyi, O.A. and Salako, E.T 2011. Teaching Social Studies from a multicultural perspectives: A practical approach for societal change in Nigeria. The journal of international social research. Vol 4(16),pp 314322.

23. Parsloe, E.; Wray, M. J. (2000). Coaching and mentoring: practical methods to improve learning. Kogan Page. ISBN 978-0-7494-3118-1.

24. Pompper, D.; Adams, J. (2006). "Under the microscope: Gender and mentor-protege relationships". Public Relations Review (Science Direct) (32): 309-315.

25. Ragins, B. R., and Kram, K.E. (2007). The handoff mentoring at work: Theory, research, and practice. Thousand Oaks, CA: Sage.

26. Thomas, K.M. (2007). Diversity dynamics in the workplace. Wadsworth-Thomson: San Francisco.

27. United Nations Development Programme. 2004. Human Development Report 2004: Cultural Liberty in Today's Diverse World. New York: United Nations

28. Williams, J. (2000). Mentoring for law enforcement. FBI Law Enforcement Bulletin, 69(3), 19-25. 